\title{
Incidence and predictors of diabetic ketoacidosis among children with diabetes in west and east Gojjam zone referral hospitals, northern Ethiopia, 2019
}

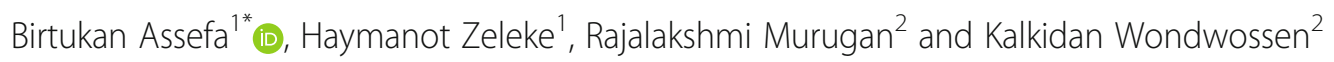

\begin{abstract}
Background: Recurrent diabetic ketoacidosis in patients with known diabetes mellitus remains a relevant problem in pediatrics with an incidence of 1-10\% per patient. Children may die because of cerebral edema and had a significant mortality (24\%) and morbidity (35\%).

Objective: We assessed the incidence and predictors of diabetic ketoacidosis among diabetes children at East and West Gojjam zone referral hospitals, North West Ethiopia, 2019.

Methods: An institution-based retrospective follow up study was conducted on children who were registered from January 1, 2014, to January 1, 2019. Epi data version 3.1 \& Stata 14 were used for data entering and analysis respectively.

Result: Out of 354 children included in the study, 207 (58.5\%) developed diabetic ketoacidosis. The overall incidence rate of diabetic ketoacidosis was 2.27/100 children/month of observation. Age < 5 years (AHR: 3.52, 95\% $\mathrm{Cl}(2.25,5.49)$, non-adherence (AHR: $1.54,95 \% \mathrm{Cl}(1.11,2.14)$, inappropriate insulin storage (AHR: $1.36,95 \% \mathrm{Cl}(1.008$, 1.85), presence of upper respiratory tract infections during diabetic ketoacidosis diagnose (AHR: $2.22,95 \% \mathrm{Cl}$ (1.11, 4.45) and preceding gastroenteritis (AHR: $2.18,95 \% \mathrm{Cl}(1.07,4.44)$ were significant predictors.

Conclusion: Age < 5 years old, non-adherence, inappropriate insulin placement at home, preceding gastroenteritis, and presence of upper respiratory tract infections at the time of diabetic ketoacidosis development were significant predictors. Hence, assessing and close monitoring as well as strengthened diabetic education should be given for the above predictors.
\end{abstract}

Keywords: Diabetic ketoacidosis, Incidence, Diabetic mellitus, And children

\footnotetext{
* Correspondence: Birtukanassefa19@gmail.com

${ }^{1}$ College of Health Sciences, Debre-Markos University, Debre-Markos, Ethiopia

Full list of author information is available at the end of the article
}

C C The Author(s). 2020 Open Access This article is licensed under a Creative Commons Attribution 4.0 International License, which permits use, sharing, adaptation, distribution and reproduction in any medium or format, as long as you give appropriate credit to the original author(s) and the source, provide a link to the Creative Commons licence, and indicate if changes were made. The images or other third party material in this article are included in the article's Creative Commons licence, unless indicated otherwise in a credit line to the material. If material is not included in the article's Creative Commons licence and your intended use is not permitted by statutory regulation or exceeds the permitted use, you will need to obtain permission directly from the copyright holder. To view a copy of this licence, visit http://creativecommons.org/licenses/by/4.0/ The Creative Commons Public Domain Dedication waiver (http://creativecommons.org/publicdomain/zero/1.0/) applies to the data made available in this article, unless otherwise stated in a credit line to the data. 


\section{Background}

Diabetic Ketoacidosis (DKA) represent a state of acute metabolic stress, results when the body suffers due to an absolute or relative insulin deficiency for the metabolism of glucose [1]. Globally, recurrent-DKA in patients with known diabetes mellitus (DM) remains a relevant problem in pediatrics. According to the international society of pediatric and adolescent diabetes, the risk of DKA in known diabetes is $1-10 \%$ per patient per year in children [2]. The incidence of recurrent DKA is varied across the world due to the difference in the quality of health care services and socioeconomic circumstances. The incidence of DKA in known diabetes children in the US was 8 per 100 person-years [3], in Sweden 3.2-3.6/100 patient-years [4], in French $0.7 \%$ [5], in Indonesia 41.4\% [6], in Germany and Austria 6\% [7] and in Italy 38.5\% [8]. Whereas in Africa the data on the incidence of DKA in known diabetes is scarce, but some studies report a high frequency of DKA in Sudan 92.1\% [9], north-western Nigeria 62.2\% [10], in South Africa $69.8 \%$ [11]. In the same way, in Ethiopia, to our knowledge the incidence of DKA in known diabetes is unstudied, rather a study in Addis Ababa showed that the prevalence of DKA at diagnosis of DM is $35.8 \%$ [12].

DKA is the most common cause of morbidity and mortality among children. It increases the risk of cerebral edema and cognitive deficits $[13,14]$. A study showed that the risk of developing cerebral edema was 12.4 per 1000 episodes of DKA, which was higher than non-DKA DM patients (3.8 per 1000). It has a significant mortality (24\%) and morbidity (35\%) [15]. On the top of that, DKA allows a crisis in terms of health care costs and missed work, and school-days. One DKA-related hospital admission ranges from US\$4125 to US\$11196 costs [16]. The risk of DKA in known diabetes increased in patients with younger age ( $<5$ yrs.), infection, insulin omission, lower socioeconomic status, and lower parental education [17]. Despite an increase in diabetes in our country, there is limited study in Ethiopia on the incidence and predictors of diabetic ketoacidosis in children thus; the study aims to fill this gab.

\section{Methods and materials}

\section{Study setting}

The study was conducted in the two referral hospitals (Debre-Markos referral hospital and Felege-Hiwot referral hospital) of East and West Gojjam zones in Amara regional state North West Ethiopia. These hospitals serve more than 3.5 million and 5 million population in their catchment area respectively. Apart from other services, both referral hospitals offer diabetic treatment services.

\section{Study design}

Five years of institution-based retrospective follow up study was conducted.

\section{Inclusion and exclusion criteria}

Children age less than 15 years old and diagnosed with DM and having follow up care from January 1, 2014, to January 1, 2019, were included and the child who was developing DKA at the first diagnosis of DM and charts which was lost during the study period was excluded from the study.

\section{Data collection}

Initially, we assessed the total DM caseload in the database on the registered follow-up chart/form from the discharge catalog of admitted patient's pediatric ward, emergency and outpatient department from January 1, 2014, to January 1, 2019. Then the medical registration numbers of all diabetic pediatric patients were sorted. After this, a simple random technique was applied to select the required sample size of 376 children with diabetic. Finally, trained BSC nurses working at diabetic clinics collected the data from registered patient charts in the hospital by using a checklist that measures the socio-demographic, clinical, treatment characteristics and information on glycemic control of the children.

\section{Outcome measures}

DKA was considered, in the context of hyperglycemia (Blood glucose measurement $>200 \mathrm{mg} / \mathrm{dl}$ or $>11 \mathrm{mmol} /$ L) and any of the following present: a blood bicarbonate level $<15 \mathrm{mmol} / \mathrm{L}$, and/or a $\mathrm{pH}<7.30$, and/or a DKA diagnosis mentioned in the medical records and/or Ketone body in the urine [2]. Appropriate insulin storage was considered in patients who store insulin in a refrigerator between 2 to 8 degree Celsius and keep away from heat and light. If a refrigerator is not available appropriate insulin storage was considered in patients who kept Vials at room temperature (20 to 25 degree Celsius) and protected from sunlight and heat for a maximum of 6 weeks, and 4 weeks (if the temperature goes up to 30 degree Celsius or within hot seasons) after initial use, in a clean plastic box (plastic container with cotton) [18].

\section{Ethical consideration}

After the approval of the proposal, ethical clearance was obtained from the school of nursing and midwifery, college of health sciences, Addis Ababa University. Then permission letter was written to Debre Markos and Felege Hiwot referral hospitals to collect the data. We had taken permission from hospital medical directors and data was kept confidential. Informed consent was not required, due to data was taken from chart review only.

\section{Statistical analysis}

The collected data were coded and entered into Epi data version 3.1 and cleaned and transferred to Stata version 14 for further analysis. The incidence rate of DKA was 
estimated per 100 DM children per month. The Kaplan Meier estimator was applied to estimate, the median time to develop DKA during the treatment period and log-rank tests, to compare survival curves. The predictors of DKA were analyzed by the Cox proportional hazard model with hazard ratio, 95\% CI. The statistical test was considered significant at a $P$ value of less than 0.05 . Covariates and proportional hazard assumptions were checked using a log-log plot and goodness of fit by Schoenfeld residual test.

\section{Results}

\section{Socio-demographic characteristics}

Out of 376 children's clinical profile reviewed, 354 were enrolled in the study. The rest of sample 22 (5.8) was incomplete data. From 354 children, more than half 159 (55.1\%) were males and more than half 189 (53.4) of them were from a rural area. The mean age of the children at the time of DM diagnosis was 8.21 years with SD \pm 3.94 years (Table 1 ).

\section{Clinical characteristics}

The majority of the 295 (83.3\%) of children have normal weight for age. Around 258 (72.9\%) have no family history of DM. The majority of children $317(89.5 \%)$ were diagnosed with type $1 \mathrm{DM}$, the rest were type $2 \mathrm{DM}$. About one-third of participants 119(33.6\%) have got preceding infection; of which 346(97.7\%) had upper respiratory tract infection (URTI) followed by $53(15 \%)$ skin fungal infection including (tinea capitis $46(86.8 \%)$, Tinea corporis $5(9.4 \%)$ and cutaneous candidiasis $2(3.8 \%)$ ) and 19(5.4\%) pneumonia (Table 2).

Nearly one-third of children 120 (33.9\%) had an acute illness at the time of DKA development. Of which 53 (14.97\%) had pneumonia followed by urinary tract infection (UTI) 28 (7.9\%) and gastroenteritis 22 (6.2\%) (Fig. 1). About 92 (26.0\%) of children had comorbidity of which 55 (15.5\%) had severe acute malnutrition (SAM) (Fig. 2) and $105(29.7 \%)$ of children were hypoglycemic, 4 (1.1\%) had acute kidney injury and $1(0.3 \%)$ had chronic kidney injury after starting to follow up for DM.

Table 1 Socio-demographic characteristics of DM diagnosed children at East \&West Gojjam Zone referral hospitals, Northwest Ethiopia, 2019

\begin{tabular}{llll}
\hline Variable & & Frequency N(354) & Percent \% \\
\hline Sex & Male & 195 & 55.1 \\
\multirow{2}{*}{ Residence } & Female & 159 & 44.9 \\
& Urban & 165 & 46.6 \\
Age & Rural & 189 & 53.4 \\
& $<5$ year & 93 & 26.3 \\
& 5 -9year & 116 & 32.8 \\
& $>$ = 10year & 145 & 41.0 \\
\hline
\end{tabular}

\section{Treatment-related variables of DM diagnosed children}

A diabetes care team is simply composed of a physician/ general practitioners, and one compressive nurse and type of diabetes teaching/education given in our setting is one-on-one training is given in the hospital by nurses at their first diagnosis of diabetes on nutritional management, insulin injection techniques, exercise, and selfmonitoring of blood glucose. One-fourth 171 (48.3\%) of the children had a history of medication adherence and about 333 (94.5) children used insulin and 8 (2.3\%) used hypoglycemic agents for treatment, but, about 13 (3.7\%) not take any drug. About 247 (69.77\%) children stored insulin appropriately at home and about three-fourth 265 (74.9) of the children had poor glycemic control.

\section{Incidence of diabetic ketoacidosis after DM diagnosis}

Out of 354 children enrolled, 207 (58.5\%) were developed DKA, with a mean follow up time of 25.72 months with 95\% CI $(24.1,27.43)$. The children have followed a minimum of 1 month and a maximum of 5 years. The incidence rate of DKA was calculated using cases/month as a denominator for the entire cohort. The overall incidence rate of DKA in the cohort was 2.27 cases per 100 children per month. The median survival time of the entire cohort was found to be 35.6 months (IQR: 18.6, 49.2). When time is gone the hazard of developing DKA is going to high which is well described through hazard estimate (Fig. 3).

\section{Long rank test to compare survival curves}

The test statistics showed that there was a significant difference in survival function for different categorical variables. These variables include age, family history, missed follow up, from preceding infection; tonsillitis, gastroenteritis, and meningitis, from acute recent illness at the time of DKA; upper respiratory tract infection, pneumonia, tonsillitis, gastroenteritis, and otitis media, children with severe malnutrition, types of drug used, medication adherence and insulin storage at home.

The median survival time for those having a history of inappropriate insulin storage at home was 33.3 months with CI $(25.3,38.1)$ and the median survival time for those who had a history of appropriate insulin storage at home was 35.8 months with $95 \%$ CI $(30.5,42.3)$. The survival time difference between the groups was found statically significant with a $P$-value of 0.0002 (Fig. 4). In addition, the median survival time for those who had a history of medication adherence was 44.3 months with $95 \%$ CI $(36.9,50.5)$ and the mean survival time for those who had a history of medication non-adherence was 27.5 months with $95 \%$ CI $(23.6,33.9)$. The survival time difference between the groups was found statically significant with $P<0.001$ (Fig. 5). 
Table 2 Clinical characteristics of DM diagnosed children at East \&West Gojjam Zone referral hospitals, Northwest Ethiopia, 2019

\begin{tabular}{|c|c|c|c|}
\hline Variable & & Frequency (354) & Percent \% \\
\hline \multirow[t]{3}{*}{ Weight for age } & Normal & 295 & 83.3 \\
\hline & Underweight & 58 & 16.4 \\
\hline & Overweight & 1 & 0.3 \\
\hline \multirow[t]{2}{*}{ Weight for height } & Normal & 306 & 86.4 \\
\hline & Underweight & 48 & 13.6 \\
\hline \multirow[t]{12}{*}{ Preceding infection } & Fungal skin infection & 53 & 15 \\
\hline & Pneumonia & 19 & 5.4 \\
\hline & Tuberculosis & 3 & 0.8 \\
\hline & Tonsillitis & 5 & 1.4 \\
\hline & Gastroenteritis & 15 & 4.2 \\
\hline & Urinary tract infection & 14 & 4 \\
\hline & Hepatitis & 5 & 1.4 \\
\hline & Otitis media & 7 & 2 \\
\hline & Chickenpox & 2 & 0.6 \\
\hline & Meningitis & 1 & 0.3 \\
\hline & Upper respiratory tract infection & 346 & 97.7 \\
\hline & Other & 18 & 5.1 \\
\hline
\end{tabular}

\section{Predictor of diabetic ketoacidosis}

The final multivariate cox proportional hazard adjusted model revealed that, the hazard of diabetic ketoacidosis decreased by $13.4 \%$ as age increased by 1 year (95\% CI $(2.34,5.709)$. The hazard of Diabetic ketoacidosis was 3.52 times in children age $<5$ years than those aged $>10$ years $(95 \%$ CI $(2.25,5.49)$. Also, the hazard of DKA in children who have preceding gastroenteritis was 2.18 times more than those who have no preceding gastroenteritis (95\% CI $(1.07,4.45)$. Similarly, the hazard of DKA in children who have an upper respiratory tract infection at the time of DKA development was 2.22 times more than those who have no respiratory tract infection at the time of DKA development 95\% CI $(1.109,4.45)$.
The hazard of DKA was 1.36 times more in children who have a history of inappropriate insulin storage at home than those children who had a history of appropriate insulin storage at home $95 \%$ CI $(1.008,1.85)$. Lastly, the hazard of DKA in children who have a history of medication non-adherence was 1.54 times more than in children who have a history of medication adherence 95\% CI (1.11, 2.14) (Table 3).

\section{Discussion}

At the end of 5 years follow up, about 207 (58.4\%) developed DKA with the overall incidence of 2.27 cases per 100 children per month (27.24 cases per 100 child-years) observation. The incidence rate of DKA in this study is

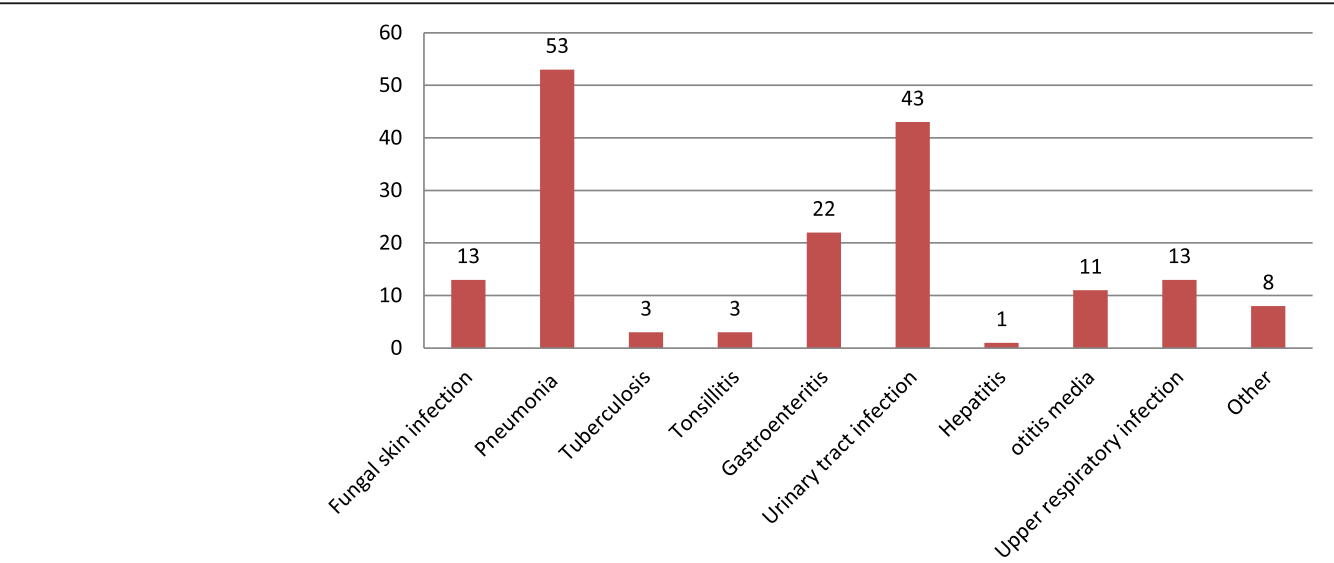

Fig. 1 Present acute illness at the time of DKA diagnose children at East \&West Gojjam zone referral hospitals, Northwest Ethiopia, 2019 


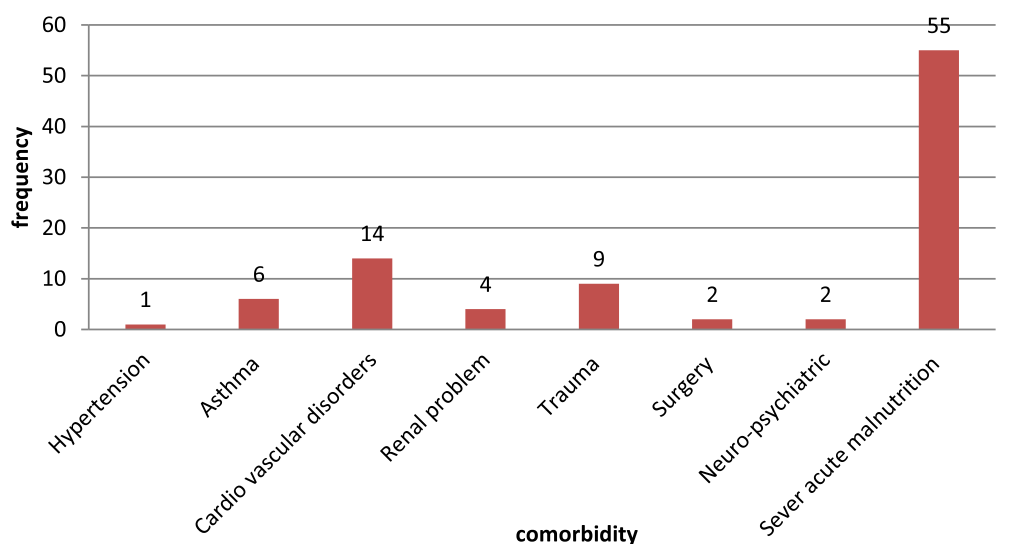

Fig. 2 Comorbidities among DM diagnosed children at East \&West Gojjam zone referral hospitals, Northwest Ethiopia, 2019

higher than studies done in the US which were 8 per 100 person-years [3], in Sweden 3.2-3.6/100 patientyears [4], the international society of pediatric and adolescent diabetes 2014 report $1-10 \%$ per patient per year [2] and Austria 8.4 to 18.4 per 100,000 per year [19]. Regarding cumulative incidence, this finding is consistent with studies done in north-western Nigeria which was $62.2 \%$ [10] and 55.5\% in Iran [20]. However, this finding is much higher than studies done in the US which was $25.5 \%$ [21], 38.5\% in Italy [8], 41.4\% in Indonesia [6], $28 \%$ in Poland [22], 40\% in southern Iraq [23]. This discrepancy might be due to difference in methodology, lifestyle, culture, economic status, access to health care facilities, and level of education of the general public.

Lack of appropriate patient (and family) education concerning the home self-management [24] may have contributed to increased incidence of DKA in Ethiopia. Thus, insufficient education and resources about selfmonitoring and DKA prevention can have a great impact on DKA existence in many patients and contribute to most of the increased morbidity and premature mortality $[25,26]$. Furthermore, poor access to health care facilities in our country [27] accompanies many patients to seek alternative treatments such as consulting traditional healers, using herbal remedies [28] prayers and rituals that encountered a delay in care which further complicating the disease process [29].

Children with age $<5$ years were more likely to develop DKA compared to age $>10$ years old. This is consistent with other previous studies conducted in the US [21], Italy [8], Southern Iraq [23]. This might be children with age $<5$-year might be more dependent on their caregiver and more venerable to medication non-adherence. Also, this age group can encounter trouble for lifestyle modifications which are the backbone for preventing the occurrence of DKA such as adhere to a diet, exercise, and self-monitoring of blood glucose level. Also, in our study, children who have medication non-adherence

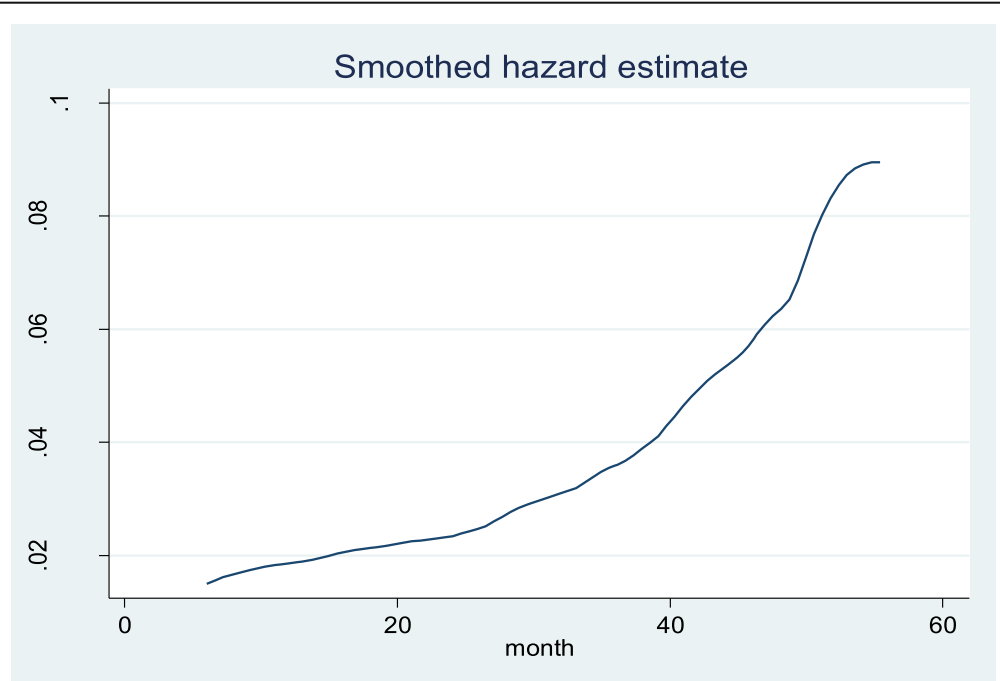

Fig. 3 The hazard estimate of DKA after DM diagnosed children at East \&West Gojjam zone referral hospitals, Northwest Ethiopia, 2019 


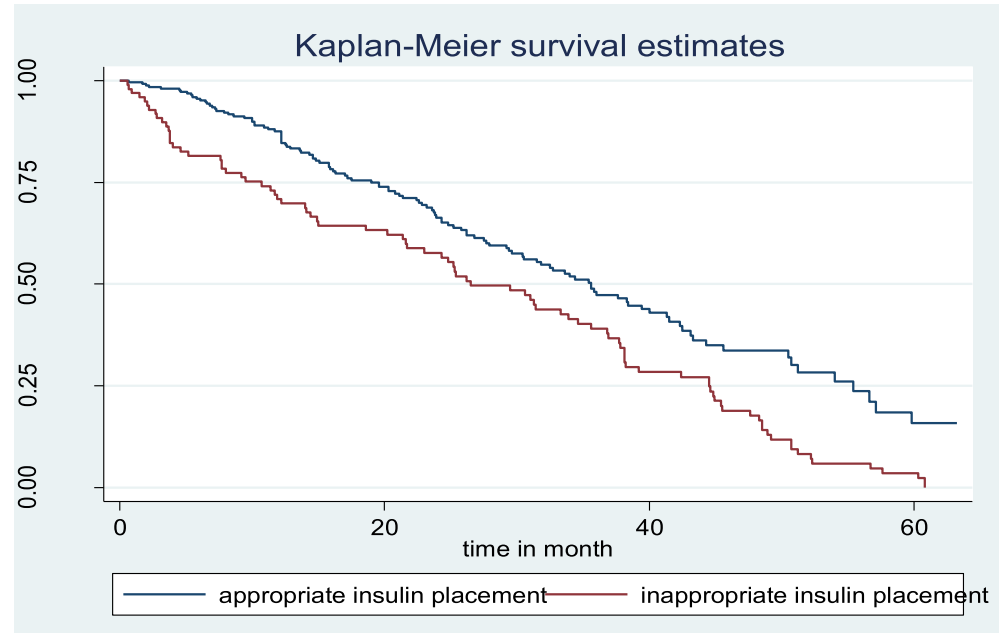

Fig. 4 Kaplan-Meier survival estimate of DKA occurrence based on insulin placement at home at East \&West Gojjam zone referral hospitals, North West Ethiopia, 2019

were more likely to develop DKA as compared to children who adhere to medication. This finding is supported by other previous studies conducted in subSaharan Africa [30], north India [31], Saudi Arabia [32], Southern Iraq [23]. This might be since DM is a chronic illness after taking medication symptoms may disappear for some time so; the children may not take their medication on time.

In this study child having a history of inappropriate insulin storage at home were more likely to develop DKA. This might be most of the participants were from rural areas and may not have appropriate storage materials like refrigerators. Besides, because of our poor diabetic education services [24] they may have inadequate knowledge about insulin storage during temperature variation and duration of storage. Lastly, in this study, children who have preceding gastroenteritis and upper respiratory tract infection at the time of DKA development were more likely to develop DKA as compared to those who have not. This is supported by the study, in Nigeria [10], subSaharan Africa [30], Malaysia [33], north India [31],

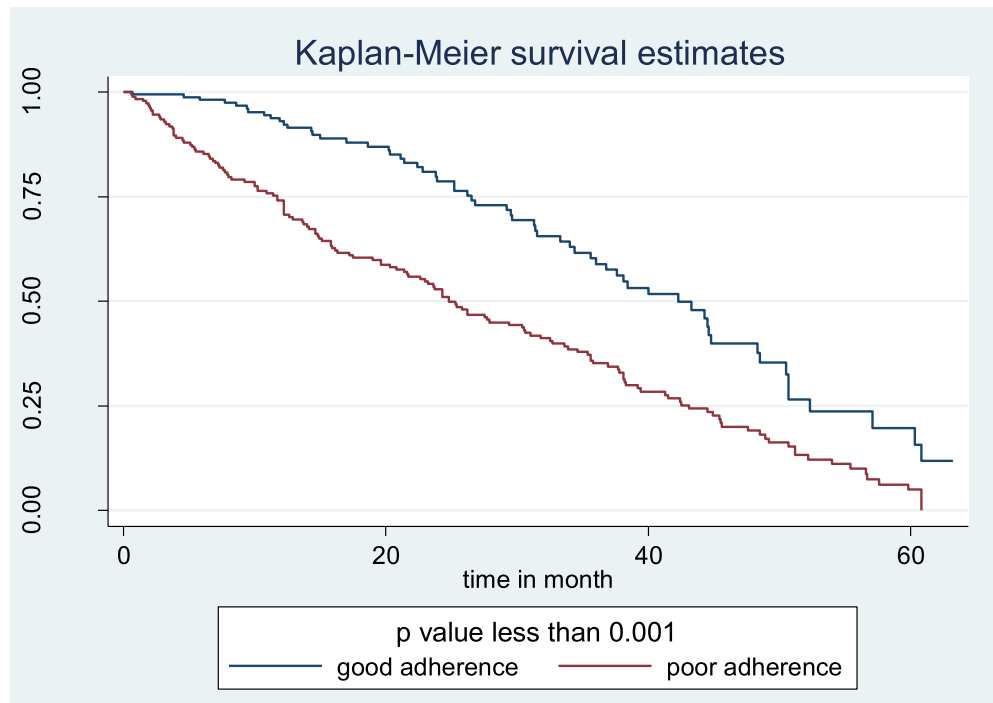

Fig. 5 Kaplan-Meier survival estimate of DKA occurrence based on medication adherence at East \&West Gojjam zone referral hospitals, North West Ethiopia, 2019 
Table 3 Cox regression analysis for predictors of DKA

\begin{tabular}{|c|c|c|c|c|c|c|c|}
\hline \multirow[t]{2}{*}{ Variable } & & & \multicolumn{2}{|c|}{ Survival status } & \multirow[t]{2}{*}{ CHR $(95 \% \mathrm{Cl})$} & \multirow[t]{2}{*}{$P$-value } & \multirow[t]{2}{*}{ AHR $(95 \% \mathrm{Cl})$} \\
\hline & & & Event & Censor & & & \\
\hline \multirow[t]{3}{*}{ Age } & $<5$ & & 59 & 34 & $4.58(3.07,6.82)$ & $<0.001^{*}$ & $3.52(2.25,5.49)$ \\
\hline & $5-10$ & & 87 & 61 & $1.76(1.18,2.62)$ & 0.065 & $1.47(0.97,2.24)$ \\
\hline & $>10$ & & 61 & 52 & 1 & & 1 \\
\hline \multirow[t]{2}{*}{ Sex } & Male & & 111 & 84 & & & 1 \\
\hline & Female & & 96 & 63 & $0.83(0.6,0.097)$ & 0.185 & $0.82(0.61,1.09)$ \\
\hline \multirow[t]{2}{*}{ Missed follow up } & Yes & & 88 & 48 & & & \\
\hline & No & & 119 & 99 & $0.75(0.57,0.99)$ & 0.172 & $0.81(0.61,1.09)$ \\
\hline \multirow[t]{2}{*}{ Insulin storage } & Appropriate & & 105 & 142 & 1 & & 1 \\
\hline & Inappropriate & & 102 & 5 & $1.98(1.51,2.62)$ & $0.044 *$ & $1.36(1.008,1.85)$ \\
\hline \multirow[t]{2}{*}{ Adherence } & Yes & & 61 & 110 & 1 & & 1 \\
\hline & No & & 146 & 37 & $2.18(0.95,2.95)$ & $0.01^{*}$ & $1.54(1.11,2.14)$ \\
\hline \multirow[t]{14}{*}{ Recent acute illness } & Pneumonia & Yes & 50 & 3 & $0.62(0.42,0.91)$ & 0.615 & $1.09(0.75,1.59)$ \\
\hline & & No & 157 & 144 & 1 & & 1 \\
\hline & upper respiratory tract infection & Yes & 13 & - & $2.44(1.39,4.31)$ & $0.024^{*}$ & $2.22(1.109,4.45)$ \\
\hline & & No & 194 & 147 & 1 & & 1 \\
\hline & Tonsillitis & Yes & 3 & - & $3.06(0.97,9.64)$ & 0.800 & $1.29(0.174,9.60)$ \\
\hline & & No & 204 & 147 & 1 & & \\
\hline & Gastroenteritis & Yes & 20 & 2 & $1.69(1.06,2.68)$ & 0.907 & $1.035(0.57,1.87)$ \\
\hline & & No & 187 & 145 & 1 & & \\
\hline & urinary tract infection & Yes & 43 & - & $1.61(1.15,2.25)$ & 0.923 & $1.73(0.67,1.41)$ \\
\hline & & No & 164 & 147 & 1 & & 1 \\
\hline & otitis media & Yes & 11 & - & $1.98(1.08,3.65)$ & 0.194 & $1.54(0.801,2.92)$ \\
\hline & & No & 196 & 147 & 1 & & 1 \\
\hline & skin fungal infection & Yes & 13 & - & $1.67(0.95,2.94)$ & 0.096 & $1.73(0.90,3.30)$ \\
\hline & & No & 194 & 147 & 1 & & \\
\hline \multirow[t]{12}{*}{ Preceding infection } & tuberculosis & Yes & 3 & - & $2.91(0.92,0.16)$ & 0.071 & $3.7(0.89-15.85)$ \\
\hline & & No & 204 & 147 & 1 & & 1 \\
\hline & Tonsillitis & Yes & 5 & - & $2.67(1.09,6.52)$ & 0.498 & $1.82(0.32,10.39)$ \\
\hline & & No & 202 & 147 & 1 & & 1 \\
\hline & gastroenteritis & Yes & 12 & 3 & $2.27(1.26,4.09)$ & $0.032^{*}$ & $2.18(1.07,4.46)$ \\
\hline & & No & 195 & 144 & 1 & & 1 \\
\hline & urinary tract infection & No & 11 & 3 & $1.68(0.91,3.09)$ & 0.189 & $1.58(0.79,3.15)$ \\
\hline & & Yes & 196 & 144 & 1 & & 1 \\
\hline & Meningitis & Yes & 1 & - & 8.28 & 0.316 & $0.18(0.006,5.13)$ \\
\hline & & No & 206 & 147 & 1 & & 1 \\
\hline & other infections & Yes & 12 & 6 & $1.41(0.78,2.54)$ & 0.446 & $1.27(0.68,2.08)$ \\
\hline & & No & 195 & 141 & 1 & & 1 \\
\hline \multirow{2}{*}{\multicolumn{2}{|c|}{ Having sever acute malnutrition }} & Yes & 42 & 13 & $1.41(1.004,1.98)$ & 0.901 & $1.02(0.69,1.50)$ \\
\hline & & No & 165 & 134 & 1 & & 1 \\
\hline
\end{tabular}

Keynote * variables which were significant at $p$-value $<0.05$ and - mean 0 observation

and Saudi Arabia [32]. This might be infection can cause excessive levels of counteracting hormones, mainly cortisol and adrenaline, which triggering an episode of
DKA. When there is gastroenteritis, there will be vomiting and diarrhea-causing dehydration and electrolyte imbalance. This causes an increase in the stress hormone. 


\section{Limitations}

Since the data were collected from medical records, patients' charts lost and incomplete data were found. These may affect the outcome of the study. Also, this study did not include the recurrence of diabetic ketoacidosis (trend) and the lack of some variables like parental factors that can't be addressed through chart review.

\section{Conclusion}

In conclusion, the incidence of DKA in known diabetes children found to be high. Children who have age $<5$ year, medication none adherence, inappropriate insulin placement at home, presence of upper respiratory tract infections at the time of DKA development, and presence of preceding gastroenteritis were predictors of DKA development at East and West Gojjam zone referral hospitals, Northwest Ethiopia. Therefore, Diabetic care clinics need to be strengthened. Diabetic clinic care should focus on assessing, close monitoring and enhancing diabetic education for patients and caregiver/families/ to over control the predicators of DKA. Finally, we recommend those variables that cannot be assessed through card review and recurrence DKA will be investigated with another study design.

\section{Abbreviations}

AHR: Adjusted hazard ratio; CHR: Crude hazard ratio; DM: Diabetic mellitus; DKA: Diabetic ketoacidosis; COPD: Chronic obstructive lung disease; HTN: Hypertension; SD: Standard deviation; IQR: Interquartile range; Cl: Confidence interval; US: United States; URTI: Upper respiratory tract infection; UTI: Urinary tract infection; SAM: Severe acute malnutrition

\section{Acknowledgments \\ We would like to express our great thanks to Addis Ababa University, College of health science school of nursing and midwifery for their willingness and support. Next, our great thanks also go to Felege-Hiwot re- ferral hospital and Debre-Markos referral hospital administrators. Lastly, we acknowledge our data collectors, supervisors, and friends that support us throughout our work.}

\section{Authors' contributions}

$\mathrm{BA}$ and $\mathrm{HZ}$ performed the analysis and interpretations. BA wrote the first draft, $H Z, R M \& K W$ contributed to the design of the study and substantive revision of the final draft. All authors read and approved the final manuscript.

\section{Funding}

The work was supported by Addis Ababa University, College of health sciences. The content is solely the responsibility of the authors and does not necessarily represent the official views of the funders. The funders had no role in study design, data collection, and analysis, decision to publish, or preparation of the manuscript.

\section{Availability of data and materials}

All materials and data are available from the corresponding author without any restriction.

\section{Ethics approval and consent to participate}

After the approval of the proposal, ethical clearance was obtained from the school of nursing and midwifery, college of health sciences, Addis Ababa University. Then permission letter was written to Debre Markos and Felege Hiwot referrals hospitals for data collection purposes. The confidentiality of the data had been kept. We had taken permission from hospitals medical directors and due to data had taken from chart review only, informed consent was not required.

\section{Consent for publication}

Not applicable.

\section{Competing interests}

The authors declare that they have no competing interests.

\section{Author details}

${ }^{1}$ College of Health Sciences, Debre-Markos University, Debre-Markos, Ethiopia. ${ }^{2}$ School of Nursing and Midwifery, College of Allied Health Sciences, Addis Ababa University, Addis Ababa, Ethiopia.

Received: 27 July 2020 Accepted: 26 October 2020

Published online: 03 November 2020

\section{References}

1. Robert Kliegman, B.F.S., Joseph St. Geme, Nina Schor, Nelson Textbook of Pediatrics. 22nd April 2015. 2

2. Wolfsdorf Jl, et al. ISPAD Clinical Practice Consensus Guidelines 2014. Diabetic ketoacidosis and hyperglycemic hyperosmolar state. Pediatr Diabetes. 2014;15(Suppl 20):154-79.

3. Rewers $A$, et al. Predictors of acute complications in children with type 1 diabetes. Jama. 2002;287(19):2511-8.

4. Hanas R, Lindgren F, Lindblad B. A 2-yr national population study of pediatric ketoacidosis in Sweden: predisposing conditions and insulin pump use. Pediatr Diabetes. 2009;10(1):33-7.

5. Rosilio M, et al. Factors associated with glycemic control. A cross-sectional nationwide study in 2,579 French children with type 1 diabetes. The French pediatric diabetes group. Diabetes Care. 1998;21(7):1146-53.

6. Rochmah N, Faizi M, Harjantien N. Diabetic ketoacidosis in children: an 11year retrospective in Surabaya, Indonesia. Paediatr Indones. 2015;55(1):40-3..

7. Fritsch $\mathrm{M}$, et al. Predictors of diabetic ketoacidosis in children and adolescents with type 1 diabetes. Experience from a large multicentre database. Pediatr Diabetes. 2011;12(4 Pt 1):307-12.

8. Zucchini $\mathrm{S}$, et al. A multicenter retrospective survey regarding diabetic ketoacidosis Management in Italian Children with type 1 diabetes. J Diabetes Res. 2016;2016:5719470.

9. Elamin A, et al. Clinical pattern of childhood type 1 (insulin-dependent) diabetes mellitus in the Sudan. Diabetologia. 1992;35(7):645-8.

10. Ugege O, Ibitoye P, Jiya N. Childhood diabetes mellitus in Sokoto, NorthWestern Nigeria: a ten year review. Sahel Med J. 2013;16:97-101.

11. Reddy, Y., Y. Ganie, and K. Pillay, Characteristics of children presenting with newly diagnosed type 1 diabetes. S Afr JChild Health; Vol 7, No 2 (2013), 2013.

12. Atkilt HS, Turago MG, Tegegne BS. Clinical characteristics of diabetic ketoacidosis in children with newly diagnosed type 1 diabetes in Addis Ababa, Ethiopia: a cross-sectional study. PLoS One. 2017;12(1):e0169666.

13. Dahlquist G, Källén B. Mortality in childhood-onset type 1 diabetes: a population-based study. Diabetes Care. 2005;28(10):2384-7.

14. Lawrence SE, et al. Population-based study of incidence and risk factors for cerebral edema in pediatric diabetic ketoacidosis. J Pediatr. 2005;146(5):688-92.

15. Edge JA, et al. The risk and outcome of cerebral oedema developing during diabetic ketoacidosis. Arch Dis Child. 2001;85(1):16-22.

16. Tieder JS, et al. Variation in resource use and readmission for diabetic ketoacidosis in children's hospitals. Pediatrics. 2013;132(2):229-36.

17. Usher-Smith JA, et al. Factors associated with the presence of diabetic ketoacidosis at diagnosis of diabetes in children and young adults: a systematic review. BMJ. 2011;343:d4092.

18. Bahendeka S, et al. EADSG guidelines: insulin storage and optimisation of injection technique in diabetes management. Diabetes Ther. 2019;10(2):341-66.

19. Schober E, Rami B, Waldhoer T. Diabetic ketoacidosis at diagnosis in Austrian children in 1989-2008: a population-based analysis. Diabetologia. 2010:53(6):1057-61.

20. Morteza Alijanpouraghamaleki ZS, Rezapour M, Bijani A, Aghajanpour F. Incidence, predisposing factors and complications of Diabetic Ketoacidosis in diabetic patients. Caspian J Pediatr. 2016;2(2):142-7.

21. Rewers A, et al. Presence of diabetic ketoacidosis at diagnosis of diabetes mellitus in youth: the search for diabetes in youth study. Pediatrics. 2008; 121(5):e1258-66.

22. Szypowska A, et al. High frequency of diabetic ketoacidosis in children with newly diagnosed type 1 diabetes. J Diabetes Rese. 2016;2016:9582793. 
23. Abbas Ali Mansour, Abdu-Alla, M.A.A.K, Predictors of Diabetic Ketoacidosis among Patients with Type 1 Diabetes Mellitus Seen in the Emergency Unit. J Adv Med Med Res, Oct 17, 2015. 11(10): p. 1-12..

24. Bahru Y, Abdulkadir J. Assessment of diabetes education in the teaching hospital, Addis Ababa, Ethiopia. Diabet Med. 1993;10(9):870-3.

25. Bui $\mathrm{H}$, et al. Is diabetic ketoacidosis at disease onset a result of missed diagnosis? J Pediatr. 2010;156(3):472-7.

26. Pambianco $\mathrm{G}$, et al. The 30-year natural history of type 1 diabetes complications: the Pittsburgh epidemiology of diabetes complications study experience. Diabetes. 2006;55(5):1463-9.

27. Woldemichael $A$, et al. Availability and inequality in accessibility of health Centre-based primary healthcare in Ethiopia. PLoS One. 2019;14(3):e0213896.

28. Mekuria $A B$, et al. Prevalence and correlates of herbal medicine use among type 2 diabetic patients in teaching Hospital in Ethiopia: a cross-sectional study. BMC Complement Altern Med. 2018:18(1):85.

29. Yared A. Predictors of traditional medical practices in illness behavior in northwestern Ethiopia: an integrated model of behavioral prediction based logistic regression analysis. Evid Based Complement Alternat Med. 2017; 2017:4186064.

30. Otieno CF, et al. Diabetic ketoacidosis: risk factors, mechanisms and management strategies in sub-Saharan Africa: a review. East Afr Med J. 2005:82(12 Suppl):S197-203.

31. Bhardwaj, P., V. Yadav, and M. Sharma, Clinical profile and outcome of the children with diabetic ketoacidosis (DKA) in hilly Himalayan state of north India. 2017, 2017. 5(12): p. 4.

32. Satti SA, Saadeldin IY, Dammas AS. Diabetic ketoacidosis in children admitted to pediatric intensive care unit of king Fahad hospital, Al-Baha, Saudi Arabia: precipitating factors, epidemiological parameters and clinical presentation. Sudanese J Paediatr. 2013;13(2):24-30.

33. Atif Usman SASS, Khan AH, Adnan AS. Profiles of diabetic ketoacidosis in multiethnic diabetic population of Malaysia. Trop J Pharm Res. 2015;14(1):179-85.

\section{Publisher's Note}

Springer Nature remains neutral with regard to jurisdictional claims in published maps and institutional affiliations.

Ready to submit your research? Choose BMC and benefit from:

- fast, convenient online submission

- thorough peer review by experienced researchers in your field

- rapid publication on acceptance

- support for research data, including large and complex data types

- gold Open Access which fosters wider collaboration and increased citations

- maximum visibility for your research: over $100 \mathrm{M}$ website views per year

At $\mathrm{BMC}$, research is always in progress.

Learn more biomedcentral.com/submissions 